\section{Flow-Through Cell Method and IVIVR for Poorly Soluble Drugs}

\author{
Catharina Wähling, Christian Schröter*, and Andrea Hanefeld \\ Merck KGaA, CMC Development, 64291 Darmstadt, Germany
}

\begin{abstract}
The percentage of poorly soluble compounds in drug discovery and development increases steadily. A variety of possibilities exists for increasing solubility and bioavailability; among them is the formation of salts. For the characterization of poorly soluble active pharmaceutical ingredients (API), it is necessary to develop appropriate analytical methods to determine relevant physicochemical properties. One important physicochemical parameter is the dissolution rate. As the flow-through cell (FTC) offers various advantages, such as operating with pH gradients and in sink conditions or applying unlimited amount of media, the FTC is particularly suitable for poorly soluble compounds. When developing an FTC method it is important to consider the physiological circumstances. By choosing the appropriate conditions for media, volume, flow rate, and so forth, it is possible to predict in vivo behavior. The focus of this work was to develop a small-scale FTC method for poorly soluble compounds designed for determining dissolution kinetics in the early development phase, where only limited amount of drug is available. The predictive power of the presented system could be demonstrated by an in vitro-in vivo relationship (IVIVR) study.
\end{abstract}

\section{INTRODUCTION}

D uring the last decades, the development of new chemical entities (NCE) has turned towards in silico modeling, combinatorial chemistry, and highthroughput screening of highly lipophilic substances. Resulting hits are characterized by high molecular weight, unmodified properties of hydrogen bonds, an increased lipophilicity, and a low solubility in aqueous media (1-3). There are different ways to overcome these constraints and enhance solubility and bioavailability: For late formulation development, enabling technologies such as solid dispersions (4), nanosizing (5), or the application of inclusion complexes (6) or SMEDDS (self-microemulsifying drug delivery system) (7) are common methods. In early stage development, various prodrugs or salts of APIs may prove beneficial. Salt formation is a well-known means for solubility enhancement $(8,9)$. Salt screenings are used to determine the physicochemical parameters of a drug substance and to identify the most suitable salt form. Dissolution kinetics is one important parameter for decision-making. Generally, it is determined via the basket method (USP Apparatus 1) or the paddle method (USP Apparatus 2). For poorly soluble compounds, the pharmacopeia (USP $<711>$ Dissolution, Ph. Eur. 5.6. 2.9.43) suggest the use of a flow-through cell (FTC). Figure 1A,B depicts the open and closed operating mode of an FTC. The open system benefits from a constant medium supply whereby sink conditions can be achieved and a differential curve type is obtained. In contrast, operating in the closed mode results in a cumulative curve progression. Concentrations can be measured online via UV-vis photometry or via HPLC after collection of the respective

*Corresponding author. volume fractions. An FTC method operating in a closed mode was developed by the FDA in 1957. In 1968 Pernarowski et al. (10) published a system with continuous flow that later served as the archetype for the basket method. Since 1981, the Fédération Internationale Pharmaceutique (FIP) has recommended FTC as an alternative to paddle and basket methods. In 1995 FTC was implemented in USP $<711>$ as Apparatus 4; Ph. Eur. followed in $2007(11,12)$. The USP contains monographs on small and large tablet cells; Ph. Eur. describes a cell for powder and granulates. Apart from these, there are several other types available (e.g., implant cells or cells for suppositories) (13). In Figure 2, the applied implant cell is presented. As the name indicates, this type of cell is generally used for implants or microcapsules with a very low flow rate (e.g., $5 \mathrm{~mL} / \mathrm{h}$ ). In this work, the cell was chosen because of its small chamber volume of only $1 \mathrm{~mL}$. One outstanding advantage of FTC is the possibility of running $\mathrm{pH}$ gradients by altering the medium composition, which mimics the physiological conditions of the gastrointestinal tract to a large extent. Other benefits are unlimited dissolution media volumes (open system), continuous sampling, and easy and time-effective sample preparation relative to the common paddle and basket methods. Disadvantages are poor temperature control within the cell, the challenging adjustment of the flow rate, and repositioning of the dosage form during the run $(14,15)$.

Important impact factors on the outcome of FTC results are flow rate, medium, temperature, and cell preparation. For selection of the right dissolution medium, one must consider the adequate simulation of physiological conditions. Therefore, the use of an organic solvent such as ethanol is questionable $(16,17)$. The Ph. Eur. proposes a set of media covering different $\mathrm{pH}$ values $(0.1 \mathrm{~N} \mathrm{HCl}, \mathrm{pH} 6.8$ phosphate buffer, etc.), the USP recommends the media 


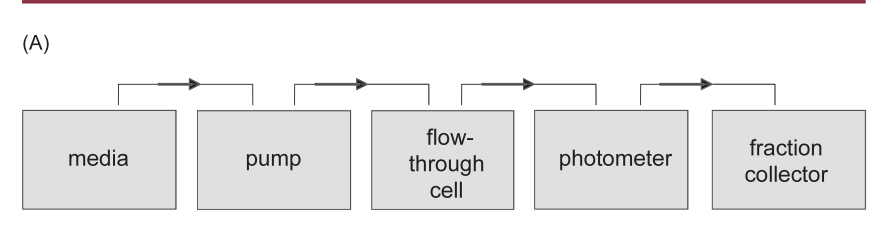

(B)

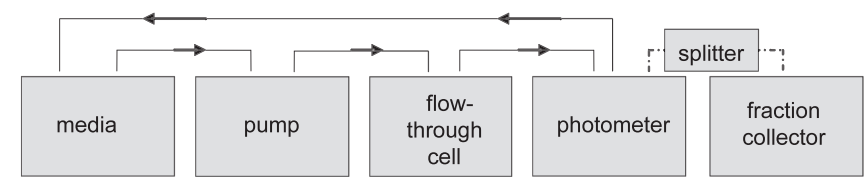

Figure 1. (A) Open system of a flow-through cell with sample analysis by UV-VIS or by HPLC and (B) closed system of a flow-through cell, the medium circulates within the system and small amounts of medium are diverted to the fraction collector for analysis by HPLC.

Simulated Gastric Fluid USP (SGF) and Simulated Intestinal Fluid USP (SIF). SGF and SIF are also listed in the guideline Waiver of In Vivo Bioavailability and Bioequivalence Studies for Immediate-Release Solid Dosage Forms Based on a Biopharmaceutics Classification System (18). Already in 1966, Bates et al. $(19,20)$ described the positive influence of physiological ingredients of bile secretion (bile salts, lecithin, cholesterol) on the dissolution of poorly soluble compounds. Today biorelevant media such as FaSSGF (Fasted-State Simulated Gastric Fluid) (21), FaSSIF (Fasted-State Simulated Intestinal Fluid), and FeSSIF (Fed-State Simulated Intestinal Fluid) (22) are well described in literature and essential for the simulation of food-dependent dissolution. Because production of these media is time consuming and expensive, they are less suitable for FTC applications in the open system (e.g., quality control) $(17,23,24)$. Alternatively, surfactants such as polyoxyethylene sorbitol oleate ( Tween $^{\circledR} 80$, a nonionic surfactant), cetyl trimethyl ammonium bromide (CTAB, a cationic surfactant), or sodium dodecyl sulfate (SDS, an anionic surfactant) can be added (25-28). When SDS is used, the composition of SIF has to be modified because of the incompatibility of SDS and potassium ions (29). It is described in the literature that SIFsp (sp is sine pancreatin) and phosphate buffer pH 6.8 R1 (according to $P$ h. Eur.), which contains equal parts of potassium dihydrogen phosphate and sodium dihydrogen phosphate, are comparable with respect to $\mathrm{pH}$, buffer capacity, ionic strength, and osmolarity $(24,30)$. Depending on concentration, surfactants serve as wetting agents below their critical micelle concentration (CMC) and as solubilizers above the CMC (23). Thus, a proportional increase of solubility with increasing surfactant concentration was found (31).

The FTC method is susceptible to interference. Hence, some issues have to be addressed before starting the measurement. Air bubbles affect parameters such as the $\mathrm{pH}$ after altering the medium, the medium flow, or the

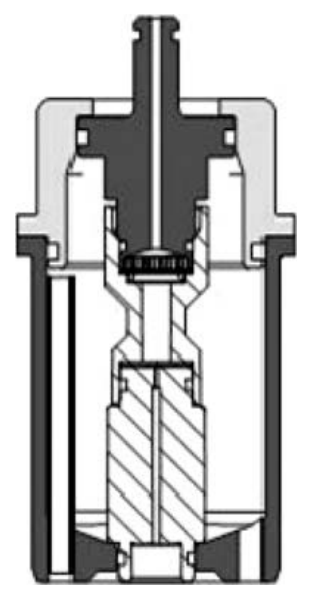

Figure 2. Cell for implants. The medium flows from bottom to top; the cell volume is $1 \mathrm{~mL}$. A filter at the top of the cell can inhibit the removal of undissolved particles.

wetting and dissolution of test substances $(25,32)$. For media degassing, techniques such as vacuum filtration, heat, ultrasound, membrane filtration, and sparging with inert gases are available $(33,34)$. USP recommends combining heating, stirring under vacuum, and vacuum filtration. For filtration, one should be aware of the influence of the choice of filter materials. Fiberglass filters are inert and can be used as volume bulk filters. Surface filters with small pore sizes (e.g., $0.45-\mu$ m nylon) are also available but tend to clog depending on the respective medium (35). Furthermore, possible adsorption on the filter material should be evaluated.

As mentioned above, there are different ways to analyze the collected volume fractions. UV-vis is the prevalent tool of analysis (36), but fiber-optical probes (immersion probes and ATR probes) also give adequate results $(37,38)$. Sensors are used in situ and have the advantage of simple insertion even into strongly absorbing test solutions or suspensions. On the other hand, sensors are often sensitive to excipients or dissolution media. Recently a dissolution tester using fiber-optical probes ( $\mu$ DISS Profiler) was launched by pION Inc, USA. Calibration tests were carried out (data not shown) applying UV-vis and ATR probes (Hellma GmbH \& Co. KG, Germany) to determine drug concentrations. For the systems tested, it was not possible to determine the relevant concentration range via the two probe systems. The absorption was too high for the immersion probe and too low for the ATR probe; what resulted was a concentration gap that could not be bridged by the fiber-optic probe systems.

Up to now, the FTC has merely gained attention in the development and characterization of APIs (39). Data acquired via FTC could be correlated well to that of the paddle method $(13,40)$ and to in vivo data $(41-44)$. Because of the widespread development of poorly soluble compounds in the pharmaceutical industry, the FTC will gain importance. 
The aim of this work was to develop an FTC method for poorly soluble compounds to determine dissolution kinetics in early development stages. This in vitro method could then be used as a substitute for animal studies. The FTC was a modified USP Apparatus 4 equipped with implant cells to cope with the low sample amounts usually available in early drug development. To evaluate the

(A)

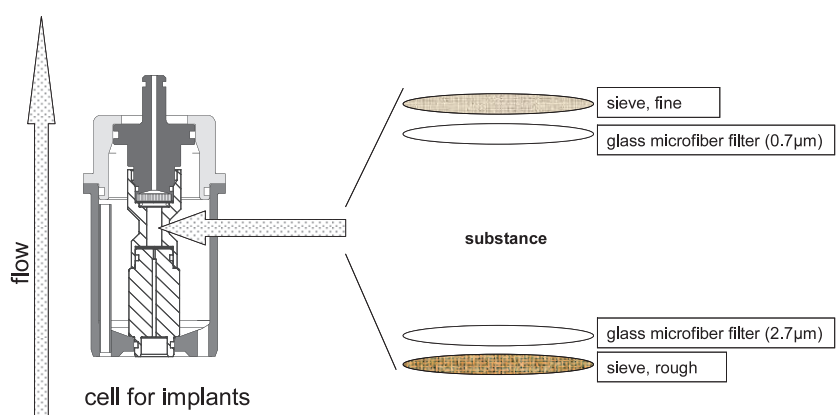

(B)

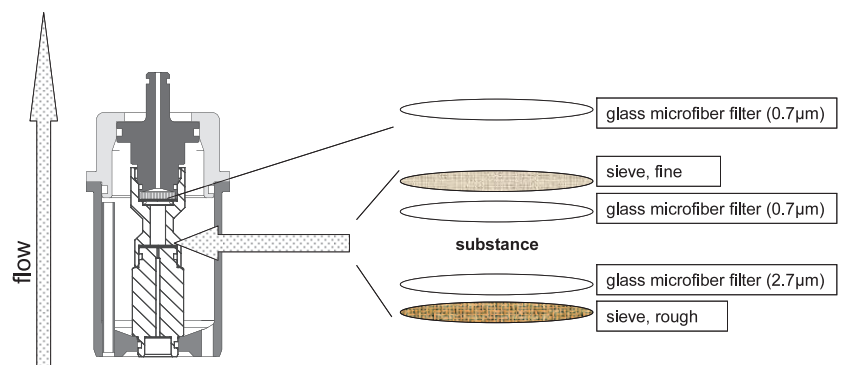
cell for implants

(C)

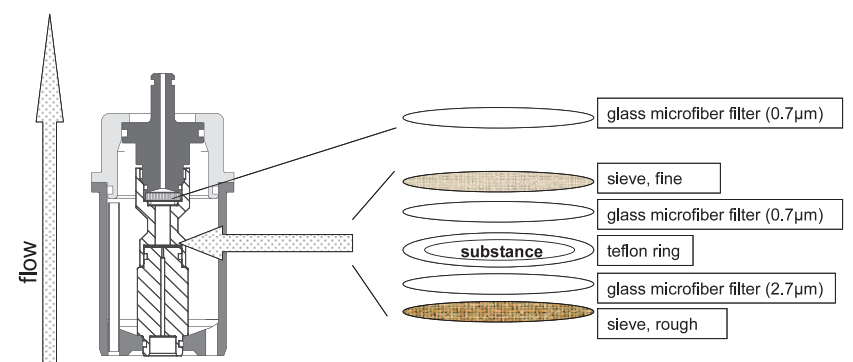

cell for implants

Figure 3. Cell preparations. (A) The substance is placed into the large sample cavity. Glass microfiber filters and sieves are located above and below the sample. (B) The substance is situated between two glass microfiber filters underneath the large sample cavity (see black line in the figure). (C) Preparation $C$ is analog preparation $B$, additionally a Teflon ring is located between two glass microfiber filters. The substance is placed into the hollow interior. influence of cell preparation on the dissolution results, different methods of preparation were compared (Figure $3 \mathrm{~A}-\mathrm{C}$ ). The great advantage of FTC is the ability to change dissolution media composition (i.e., pH gradients). A change in $\mathrm{pH}$ from 1.2 to 6.8 was applied in the method. The acidic APIs diclofenac and meclofenamic acid together with their sodium and diethylamine (DEA) salts were chosen as poorly soluble model substances. Diclofenac is classified as a Biopharmaceutical Classification System (BCS) Type II compound (45). It was demonstrated that reproducible results could be obtained with the developed flow-through method. IVIVR proved a qualitative relationship between the in vitro data and the in vivo data that are collected in rats. The literature $(46,47)$ also describes a feasible comparability in oral absorption of diclofenac between humans and rats.

\section{MATERIALS AND METHODS \\ Materials}

The listed $\mathrm{p} K_{\mathrm{a}}$ values for diclofenac and meclofenamic acid are 4.20 and 4.03, respectively (Figure 4A,B) (48).

The calculated solubilities in $29 \mathrm{mM}$ phosphate buffer (pH 7.4) are $2.37 \mu \mathrm{g} / \mathrm{mL}$ for diclofenac and $0.03 \mu \mathrm{g} / \mathrm{mL}$ for meclofenamic acid (calculated with WSKOWWIN Program, Version 1.41, Syracuse Research Corporation, USA). Diclofenac sodium was purchased from Caesar \& Loretz, Germany, and meclofenamate sodium was purchased from ABCR GmbH \& Co KG, Germany. All other substances were acquired from Merck KGaA, Germany.

(A)<smiles>O=C(O)Cc1ccccc1Nc1c(Cl)cccc1Cl</smiles>

(B)<smiles>Cc1ccc(Cl)c(Nc2ccccc2C(=O)O)c1Cl</smiles>

Figure 4. Chemical structures of $(A)$ diclofenac $(M W=296.2)$ and (B) meclofenamic acid ( $M W=296.2$ ). 
Table 1. Content of Simulated Gastric Fluid without Pepsin (SGFsp+), pH 1.2

\begin{tabular}{lc}
\hline SGFsp+ \\
\hline sodium chloride & $2.0 \mathrm{~g}$ \\
\hline hydrochloric acid $37 \%$ & $7.0 \mathrm{~mL}$ \\
\hline distilled water & q. s. $1000 \mathrm{~mL}$ \\
\hline sodium dodecyl sulfate & $0.01 \%$ \\
\hline
\end{tabular}

\section{Preparation of Salts}

The free acids of diclofenac and meclofenamic were extracted from their sodium salts in ethyl acetate. Then salts were prepared by dissolving the free acid of diclofenac or meclofenamic acid in acetone and subsequently mixing with an equimolar amount of base (counterion, diethylamine) dissolved in the same solvent. Both the free acids and precipitated salts of diclofenac and meclofenamate diethylamine (DEA) were washed with organic solvent and dried in a vacuum desiccator.

\section{Elemental Analysis (EA)}

To confirm the salt conversion, elemental analysis was performed. The elements $\mathrm{C}, \mathrm{H}$, and $\mathrm{N}$ were determined by a Vario EL III (Elementar Analysensysteme GmbH, Germany).

\section{Particle Size Distribution (PSD)}

The particle size distribution was analyzed by static light scattering with a Mastersizer 2000 (Malvern Instruments LTD, UK). A silicon oil suspension $(2.5 \mathrm{mg} / \mathrm{mL})$ was measured in ten replicates. The obtained values of $d[0.10], d[0.50]$, and $d[0.90]$ were calculated by Fraunhofer approximation (49).

\section{Tensiometry}

The L. du Noüy ring method was used to determine the surface tension of the media (Tensiometer $\mathrm{K} 12$, Krüss $\mathrm{GmbH}$, Germany). The temperature was set to $37^{\circ} \mathrm{C}$. Concentrations of $0 \%, 0.01 \%, 0.015 \%, 0.02 \%, 0.03 \%, 0.1 \%$, $0.2 \%, 0.5 \%$, and $1 \%$ sodium dodecylsulfate in SGFsp and So-SIFsp were measured $(n=10)$.

\section{Flow-Through Cell (FTC)}

A flow-through cell similar to USP Apparatus 4 was used. The cells were operated in the open mode, and implant cells were chosen as the most suitable cell type (Figure 2). Five milligrams of drug substance was placed in the cell (preparation C, see below). Experiments were done in triplicate. Flow rate was adjusted to $2 \mathrm{~mL} / \mathrm{min}$ and kept constant within an allowed $\pm 5 \%$ tolerance (peristaltic pump IPC 12, Ismatec Laboratoriumstechnik $\mathrm{GmbH}$, Germany). The temperature was set to $37^{\circ} \mathrm{C}$. Via media alteration, a pH gradient was achieved; the medium changed from SGFsp + to So-SIFsp+ after $45 \mathrm{~min}$. Samples were collected after $5,10,15,30,45,50,55,60,65,70,80,90$, 105,120 , and $135 \mathrm{~min}$. The samples were analyzed by HPLC.
Table 2. Content of Sodium Simulated Intestinal Fluid without Pancreatin (So-SIFsp+), pH 6.8

\begin{tabular}{lc}
\hline & So-SIFsp+ \\
\hline sodium dihydrogen phosphate & $6.0 \mathrm{~g}$ \\
\hline $0.2 \mathrm{~N}$ sodium hydroxide & $77 \mathrm{~mL}$ \\
\hline distilled water & q.s. $1000 \mathrm{~mL}$ \\
\hline $0.2 \mathrm{~N}$ sodium hydroxide & q.s. $\mathrm{pH} 6.8$ \\
\hline sodium dodecyl sulfate & $0.1 \%$ \\
\hline
\end{tabular}

\section{Cell Preparation}

Three different cell preparations were tested and compared (Figure 3). Carbamezepine was applied as a physicochemically relevant test substance, and SGFsp (see below) was used as dissolution medium. In cell preparation A (Figure 3A), the substance was inserted in the large sample cavity. Glass microfiber filters (Whatman plc., UK) delimited the cell below (retention capacity of $2.7 \mu \mathrm{m}$ ) and above (retention capacity of $0.7 \mu \mathrm{m}$ ). Figure $3 \mathrm{~B}$ shows cell preparation $\mathrm{B}$. The substance was filled on a microfiber filter below the large sample cavity and fixed by another filter on top (see black line in Figure 3B). A third glass microfiber filter (retention capacity of $0.7 \mu \mathrm{m}$ ) was located at the top of the cell in case dissolved substances precipitated in the large sample cavity. Cell preparation $C$ is shown in Figure 3C. It was identical to preparation B, but additionally a Teflon ring was sited between the two glass microfiber filters and the substance was placed into the hollow interior. The problem that arose in cell preparation $B$ was that the substance did not cover the entire diameter of the cell $(15 \mathrm{~mm})$, and so the medium did not pass through the whole substance evenly. The problem was solved by the addition of a Teflon ring. Measurements were conducted 6-fold per preparation type $(n=6)$.

\section{Media}

The media Simulated Gastric Fluid sine pepsin (SGFsp) and "Sodium"-Simulated Intestinal Fluid sine pancreatin (So-SIFsp) were used (18). Potassium was replaced by an equimolar amount of sodium because of the incompatibility of potassium with dodecylsulfate. For compositions, see Tables 1 and 2. When sodium dodecylsulfate was added to the media, a"+" was added to the name (i.e., SGFsp+ and So-SIFsp+). The media were degassed with a Dosaprep X8 (Dosatec GmbH, Germany).

\section{Evaluation}

The parameter dissolution efficiency (D.E.) (50) describes the ratio between the area under the curve until time $t \int_{0}^{t} y^{*} d t$ and the total area $y_{100}{ }^{t}$ :

$$
D . E .=\frac{\int_{0}^{t} y^{*} d t}{y_{100}^{t}} \times 100 \%
$$


In this work, the area under the curve for the time window between 45 and 80 min (see below) was applied for calculating D.E. because differences between the salts at the beginning of a defined dissolution time could be described best. The area under the curve (cumulative data) was calculated via the trapezoidal rule by eq 2 .

$$
\operatorname{AUC}\left(0 \rightarrow t_{n}\right)=\frac{1}{2} \sum_{i=1}^{n}\left(c_{i-1}+c_{i}\right)\left(t_{i}-t_{i-1}\right)
$$

If only parts of the curve are described, this is quoted in the index of the D.E. parameter. For weak acids, the dissolution part of interest is located in the conditions of the upper intestine. So the values between $45 \mathrm{~min}$ and $80 \mathrm{~min}$ were included in the analysis because after $45 \mathrm{~min}$, the medium was changed to So-SIFsp+. Therefore, the index 45-80 is implemented in D.E. ${ }^{45-80}$. If weak bases or nonionizable compounds are determined, other conditions must be defined (e.g., for weak bases, acidic media, and appropriate dissolution time frame, D.E. ${ }^{0-10}$ ). Because D.E. describes only the first part of the curve, it is important to capture also the shape of the total curve.

\section{HPLC Method}

All samples were analyzed by HPLC from Merck-Hitachi with the components D-7000 Interface, L-7400 UV-Detector, L-7100 Pump (2x), L-7360 Column Oven, and L-7250 Programmable Autosampler. The HPLC software EZChrom Elite Client, Version 3.0 (Scientific Software International Inc, USA) was used. Solvent A was composed of 95:5 water/acetonitrile $\left(\mathrm{H}_{2} \mathrm{O} / \mathrm{ACN}\right)$ with $120 \mu \mathrm{L} / \mathrm{L}$ ammonia (25\%) and $59 \mu \mathrm{L} / \mathrm{L}$ formic acid ( $\mathrm{pH}$ 6.0). Solvent B consisted of $5: 95 \mathrm{H}_{2} \mathrm{O} / \mathrm{ACN}$ with the same additives as solvent $A$. The column was a Zorbax Eclipse Plus C18, $4.6 \times 50 \mathrm{~mm}$, 3.5- $\mu \mathrm{m}$ (Agilent Technologies Inc., USA). The flow rate was $3 \mathrm{~mL} / \mathrm{min}$, and the wavelength was $214 \mathrm{~nm}$. A gradient was applied.

\section{Animal Studies}

The animal studies were performed on male Wistar rats that had body weights of 200-300 g. Animals were dosed at $5 \mathrm{mg} / \mathrm{kg}$ body weight calculated on the free acid. The drug was applied orally in mini capsules (PC caps size 9, Qualicaps Inc, USA) by gavage. For each substance (free acids and their respective sodium and DEA salts), experiments were performed in triplicate. Fasting started $12 \mathrm{~h}$ before the start of the experiment. The rats were fed $2 \mathrm{~h}$ after the start, and water was provided during the whole experiment. Blood samples were tapped from the fundus of the eye at 20,40,60,120,240, $480 \mathrm{~min}$, and $24 \mathrm{~h}$ after application. Before each treatment, the rats were anaesthetized with isoflurane. An anticoagulant solution of $0.5 \mathrm{M}$ acetate $\mathrm{pH} 4.2$ containing EDTA at $10 \mathrm{~g} / \mathrm{L}$ was added to the blood samples. Afterward the blood was centrifuged, and the plasma was used for analysis.

The determination of drug levels in plasma probes was performed with HPLC-MS/MS (Agilent Technologies Inc, USA and Applied Biosystems/ MDS Sciex, USA). The internal

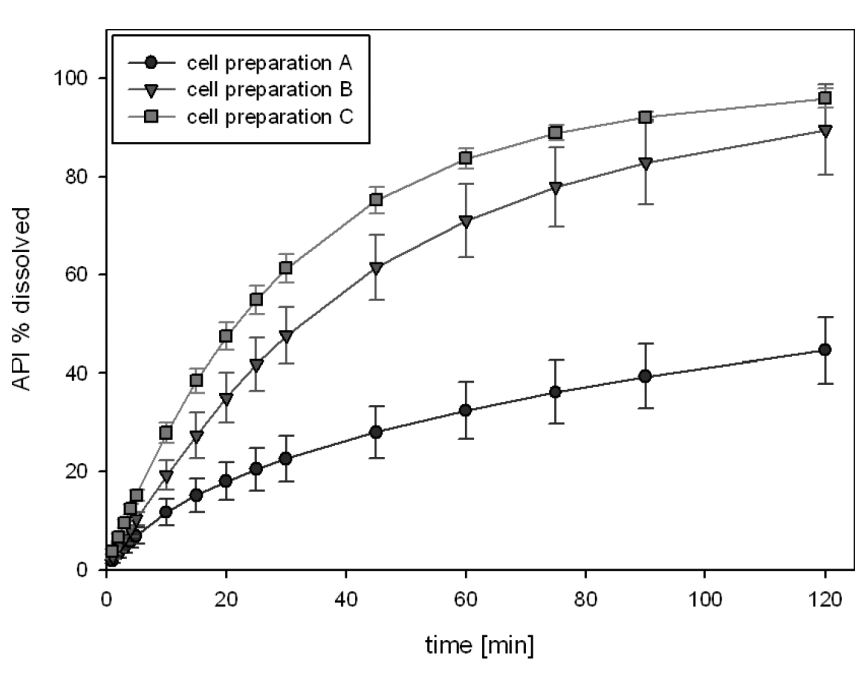

Figure 5. Influence of different cell preparations on dissolution $(n=6)$. Carbamazepine was tested in SGFsp. Preparation C shows the highest dissolution rate and a small standard deviation.

standard used was fenoprofene. Methanol was added to the plasma probes to achieve complete precipitation of protein.

\section{In Vitro-In Vivo Relationship (IVIVR)}

For qualitative assessment, rank orders within an IVIVR are determined $(39,51)$. They are also known as level D within in vitro-in vivo correlations (IVIVC) (52). In early development phases, the achievement of IVIVRs gives direction to formulation strategies. To display the rank order of in vitro and in vivo data, in vitro values were tabulated against the in vivo data. The $C_{\max }$ values $(\mathrm{ng} / \mathrm{mL})$ of the compounds were plotted versus D.E. ${ }^{45-80}$ values.

\section{RESULTS \\ Flow-Through Cell \\ Cell Preparation}

Figure 5 represents the influence of different preparation techniques on dissolution profiles. It can be seen that loading the large sample cavity has a negative impact on dissolution (A). After 2 h only $40 \%$ of the drug substance was dissolved. A comparison of methods $B$ and $C$ shows that $C$ is advantageous due to lower standard deviations. Therefore, method $C$ was applied in all subsequent measurements.

\section{Media}

The CMC of SDS in water was approximately $0.2 \%$ and correlated well with literature data (29) (Figure 6). The result for SGFsp+ was $0.03 \%$, which was confirmed by Zhao (53). The CMC in So-SIFsp+ was $0.04 \%$, which agrees with the results of Gander (54). The difference between SGFsp+ and So-SIFsp+ was due to differences in the ionic strength of the media (20). In SGFsp+, SDS was added in a concentration of $0.01 \%$, as the surface tension at this concentration was close to that of human gastric medium, $35-43 \mathrm{mN} / \mathrm{m}$ (55) and $43-54 \mathrm{mN} / \mathrm{m}$ (56). SDS at $0.1 \%$ was 


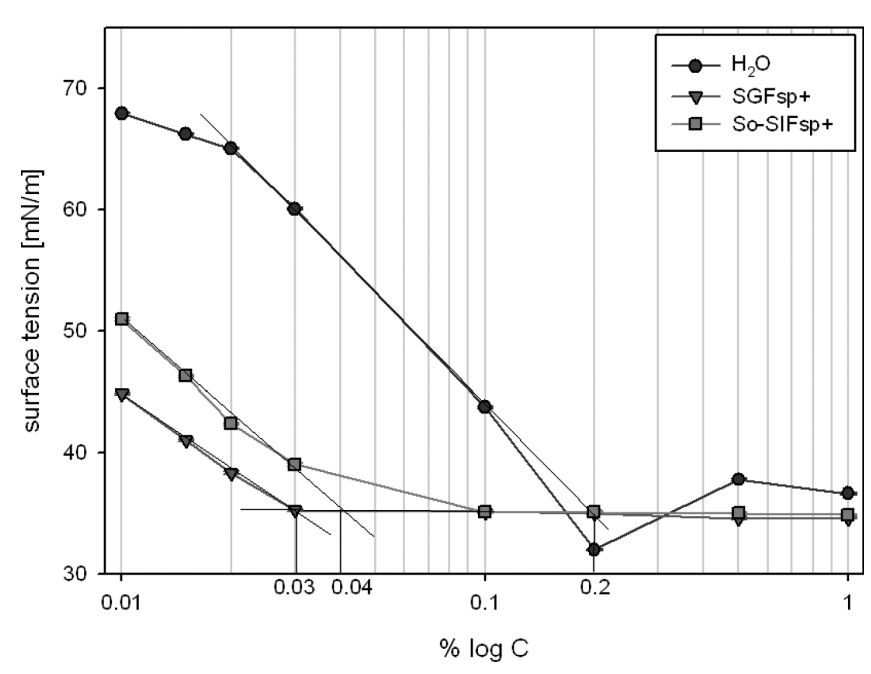

Figure 6. Surface tension of SDS in water (CMC at 0.2\%), SGFsp+ (CMC at $0.03 \%)$, and So-SIFsp+ (CMC at $0.04 \%)$ at $37^{\circ} \mathrm{C}(n=10)$.

chosen for So-SIFsp+ because the concentration should be close to the determined CMC as well as to physiological conditions.

\section{Diclofenac and Salts}

Elemental Analysis

The measured contents of $\mathrm{C}, \mathrm{N}$, and $\mathrm{H}$ agree with the expected values. The free acid diclofenac had $56.5 \% \mathrm{C}$ (calculated: $56.5 \%), 4.6 \% \mathrm{~N}(4.7 \%)$, and 3.5\% H (3.7\%); diclofenac sodium contained $52.7 \%$ C (52.6\%), $4.4 \% \mathrm{~N}$ (4.4\%), and 3.1\% H (3.5\%); and diclofenac DEA contained $58.3 \% \mathrm{C}(58.3 \%), 7.5 \% \mathrm{~N}(7.6 \%)$, and $5.7 \% \mathrm{H}(6.0 \%)$.

\section{Particle Size Distribution}

In Table 3, the PSD of diclofenac and its salts are shown. Diclofenac DEA shows the highest mean particle size and diclofenac sodium the smallest. The salts range in values between the extremes.

\section{In Vitro Results (FTC)}

Figure 7 depicts the differential dissolution profiles of the diclofenac salts. After media change (45 min), rapid dissolution of diclofenac DEA and diclofenac sodium

Table 3. Particle Size Distribution (PSD), D.E.45-80 (in vitro), and Pharmacokinetic Data ( $C_{\max }, t_{\text {max }}$ AUC) of Diclofenac, Diclofenac Sodium, and Diclofenac DEA

\begin{tabular}{|c|c|c|c|c|c|c|c|}
\hline & PSD & {$[\mu \mathrm{m}]$} & & D.E. ${ }^{45-80}$ & $C_{\max }$ & $t_{\max }$ & $A U C^{0-24}$ \\
\hline & $d(0.10)$ & $d(0.50)$ & $d(0.90)$ & $\%$ & (ng/mL) & (min) & (h*ng/MI) \\
\hline diclofenac & 1.5 & 6.4 & 37.8 & 56.30 & 818.0 & 120 & 3334.1 \\
\hline - sodium & 1.1 & 4.5 & 24.3 & 65.43 & 2550.0 & 20 & 2652.9 \\
\hline - DEA & 2.8 & 20.8 & 59.1 & 89.24 & 3355.0 & 20 & 4247.5 \\
\hline
\end{tabular}

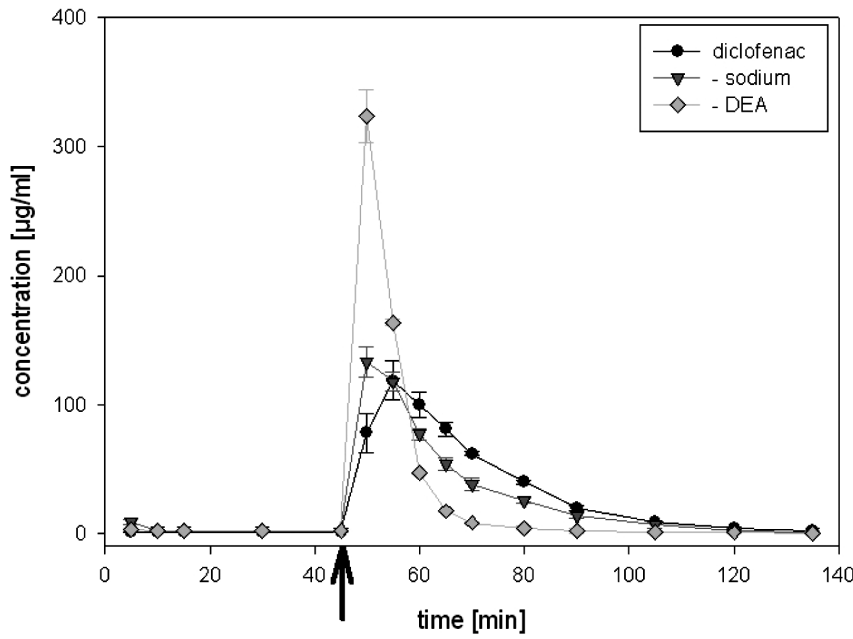

Figure 7. In vitro results of diclofenac, diclofenac sodium, and diclofenac DEA. Diclofenac DEA displays the fastest dissolution $\rightarrow$ denotes medium change differential curve, $n=3$ ).

was observed. The unbound acid reached maximum dissolution 5 min later but still reached 100\%.D.E. ${ }^{45-80}$ values are listed in Table 3.

\section{In Vivo Results}

The pharmacokinetic study revealed a generally more rapid dissolution of diclofenac and its sodium and DEA salts (Figure 8). The DEA salt showed the highest absorption at $C_{\max }=3355.0 \mathrm{ng} / \mathrm{mL}$ at $t_{\max }=20 \mathrm{~min}$, followed by the sodium salt with $C_{\max }=2550.0 \mathrm{ng} / \mathrm{mL}$ at $t_{\max }=20 \mathrm{~min}$. As for the in vitro data, the acid reached a significantly lower $C_{\max }$ of $818.0 \mathrm{ng} / \mathrm{mL}$ after a period of $2 \mathrm{~h}\left(t_{\max }=120 \mathrm{~min}\right)$. Pharmacokinetic data are listed in Table 3. The area under the curve $(A \cup C)$ was calculated via the trapezoidal rule from 0 to $24 \mathrm{~h}$. Because of single data sets missing for

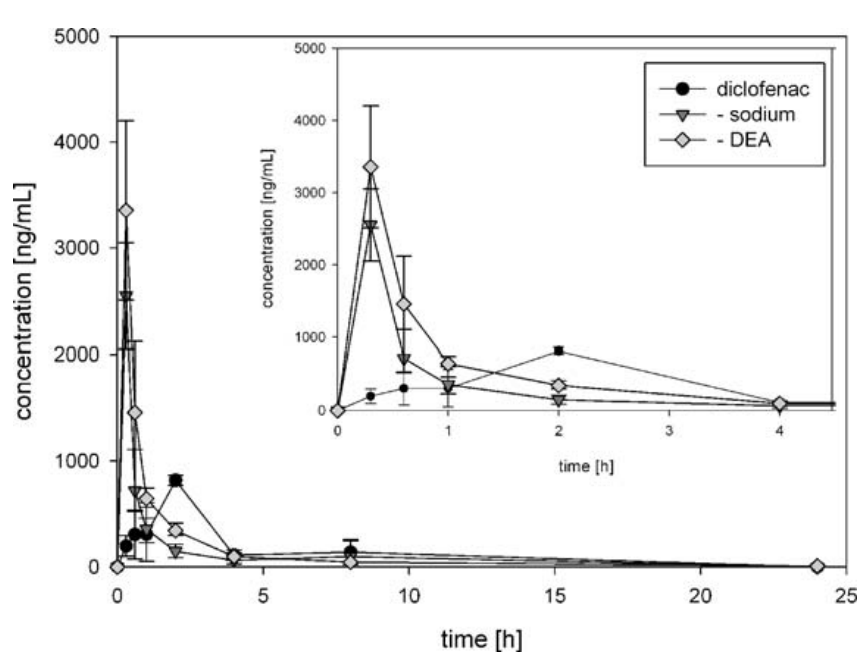

Figure 8. In vivo results of diclofenac, diclofenac sodium, and diclofenac $D E A$ in rats. Diclofenac DEA shows fastest absorption. (Mean values are listed; error bars denote minima and maxima). 


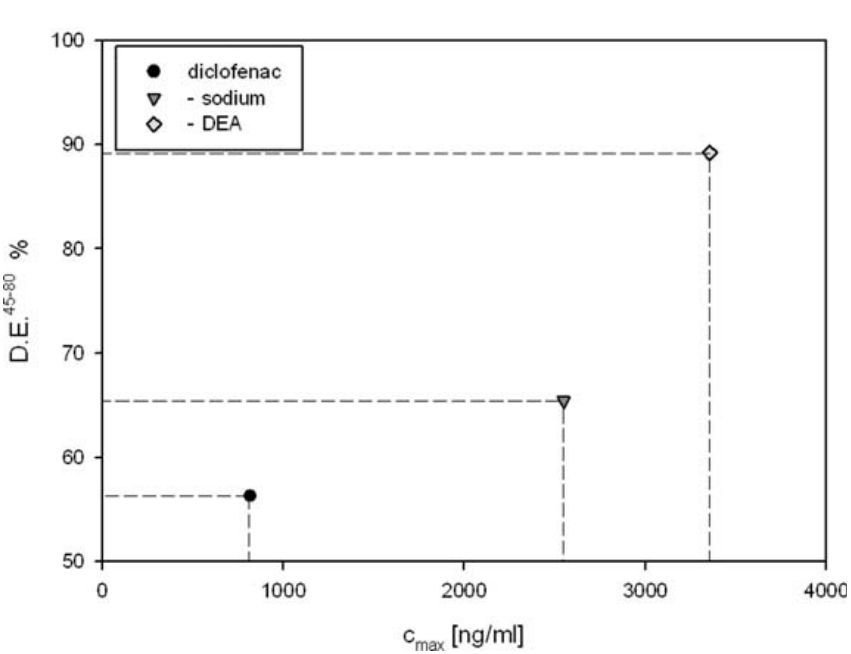

Figure 9. In vitro-in vivo relationship of diclofenac, diclofenac sodium, and diclofenac DEA. $C_{\max }\left(\mathrm{ng} / \mathrm{mL}\right.$, in vivo) versus $\%$ D.E. ${ }^{45-80}$ (in vitro) is presented. The figure illustrates a good relationship between the in vitro and in vivo data.

some of the test animals, the standard deviation could not always be calculated. Therefore, error bars denote the minimum and values in the figure.

In Vitro-In Vivo Relationship of Diclofenac and Salts

The in vitro ranking (diclofenac DEA > diclofenac sodium $>$ diclofenac) is confirmed by the in vivo results (Figure 9).

\section{Meclofenamic Acid and Salts}

Elemental Analysis

Meclofenamic acid contained $56.7 \% \mathrm{C}$ (calculated: $56.5 \%), 4.6 \% \mathrm{~N}(4.7 \%)$ and $3.4 \% \mathrm{H}(3.7 \%)$. Meclofenamate sodium results were $50.0 \% \mathrm{C}(52.6 \%), 4.1 \% \mathrm{~N}(4.4 \%)$ and $3.3 \% \mathrm{H}(3.5 \%)$ and meclofenamate DEA contained $58.4 \% \mathrm{C}$ (58.3\%), 7.5\% N (7.6\%) and 5.5\% H (6.0\%). The measured contents of $\mathrm{C}, \mathrm{N}$, and $\mathrm{H}$ were in the accepted range.

\section{Particle Size Distribution}

The PSD of meclofenamic acid and its sodium and DEA salts are presented in Table 4. The free acid and the sodium salt are comparable in their PSD; the DEA shows higher values for $d(0.10), d(0.50)$ and $d(0.90)$.

Table 4. Particle Size Distribution (PSD), D.E. ${ }^{45-80}$ (in vitro), and Pharmacokinetic Data $\left(\mathrm{C}_{\max }, \mathbf{t}_{\max }\right.$ AUC) of Meclofenamic Acid, Meclofenamate Sodium, and Meclofenamate DEA

\begin{tabular}{|c|c|c|c|c|c|c|c|}
\hline & PSD & {$[\mu \mathrm{m}]$} & & D.E. ${ }^{45-80}$ & $C_{\max }$ & $t_{\max }$ & $A U C^{0-24}$ \\
\hline & \multicolumn{3}{|c|}{$d(0.10) d(0.50) d(0.90)$} & $\%$ & \multicolumn{3}{|c|}{ (ng/mL) (min) (h*ng/mL) } \\
\hline $\begin{array}{l}\text { meclofenamic } \\
\text { acid }\end{array}$ & 1.2 & 5.1 & 28.8 & 4.83 & 172.5 & 240 & 1818.8 \\
\hline - sodium & 1.2 & 5.3 & 22.1 & 13.88 & 3725.0 & 20 & 11327.0 \\
\hline - DEA & 2.3 & 18.8 & 70.8 & 6.84 & 1294.5 & 60 & 4636.7 \\
\hline
\end{tabular}

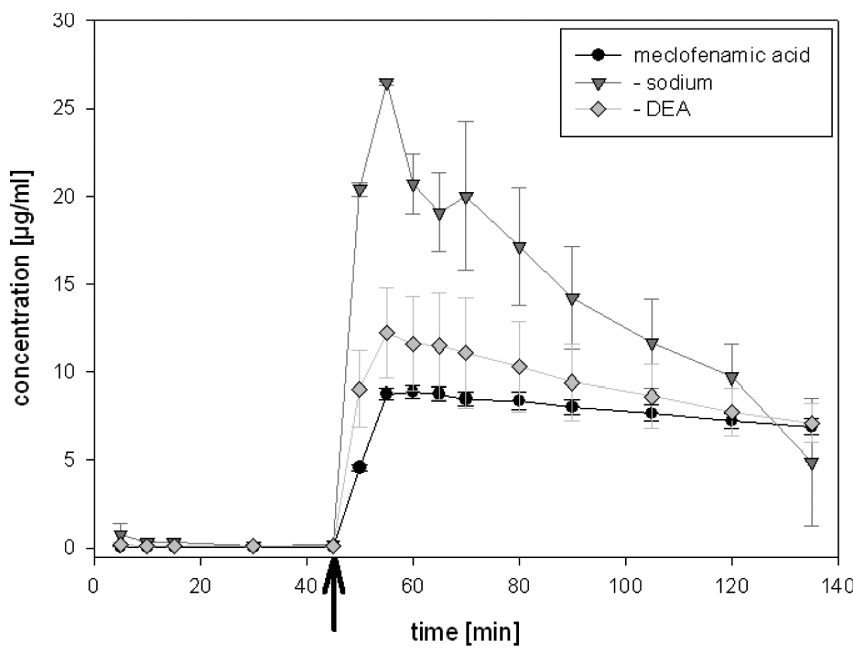

Figure 10. In vitro results of meclofenamic acid, meclofenamate sodium, and meclofenamate DEA. Meclofenamate sodium shows the fastest dissolution $(\rightarrow$ denotes medium change, differential curve, $n=3$ ).

In Vitro Results (FTC)

Figure 10 displays the dissolution profiles of meclofenamate salts. It is remarkable that meclofenamate sodium shows the highest dissolution whereas meclofenamate DEA reveals a significantly lower profile. As expected, dissolution of the free acid was the lowest. The D.E. ${ }^{45-80}$ values are listed in Table 4.

\section{In Vivo Results}

In addition, the meclofenamate-type substances displayed a rapid absorption (Figure 11). In contrast to the diclofenac salts, the rank order changed. Meclofenamate sodium showed the highest absorption with $C_{\max }=$ $3725.0 \mathrm{ng} / \mathrm{mL}$ at $t_{\max }=20 \mathrm{~min}$, followed by meclofenamate

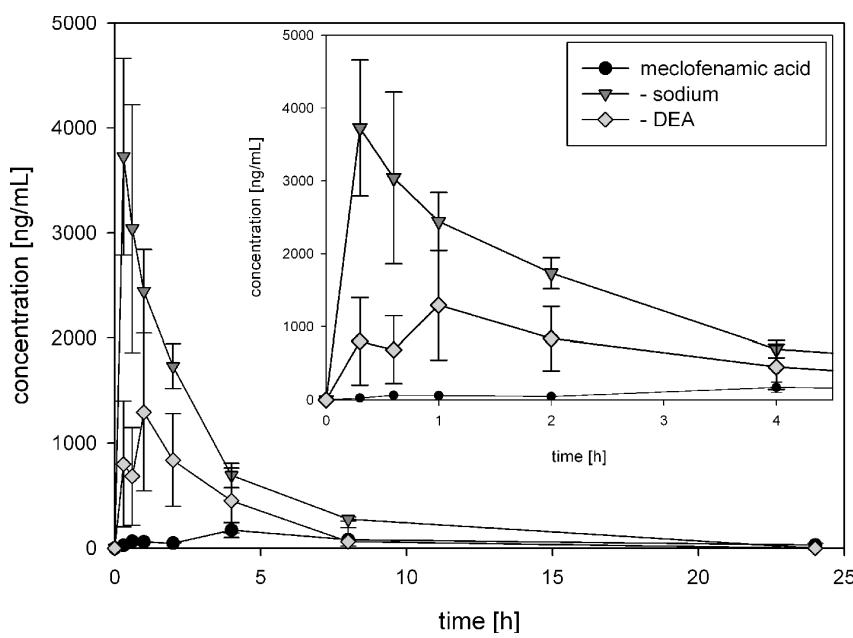

Figure 11. In vivo results of meclofenamic acid, meclofenamate sodium, and meclofenamate DEA in rats. Meclofenamate sodium shows the highest absorption. (Mean values are listed; error bars denote minima and maxima.) 


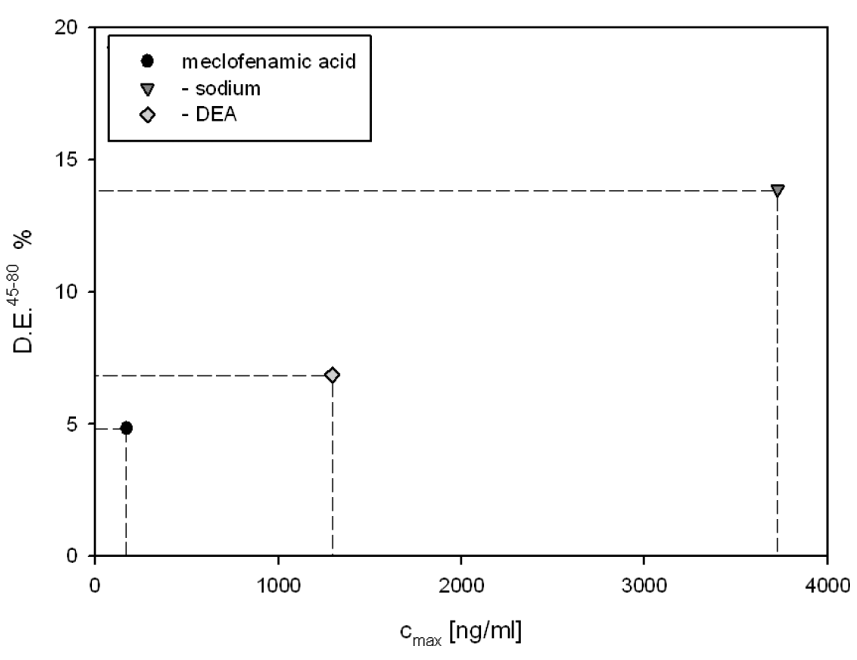

Figure 12. In vitro-in vivo relationship of meclofenamic acid, meclofenamate sodium, and meclofenamate DEA. $C_{\max }(\mathrm{ng} / \mathrm{mL}$, in vivo) plotted versus D.E. ${ }^{45-80} \%$ (in vitro). Data demonstrate a good relationship between in vitro and in vivo results.

DEA with $C_{\max }=1294.5 \mathrm{ng} / \mathrm{mL}$ at $t_{\max }=60 \mathrm{~min}$. The free acid reaches $t_{\max }$ after $240 \mathrm{~min}$ and $C_{\max }$ is only $172.5 \mathrm{ng} / \mathrm{mL}$ (Table 4). These data show the great benefit of salts in comparison to the acid. As for diclofenac and salts, not all data for all three rats per compound could be included in the calculation. Therefore, error bars represent the minimum and maximum values in the figure.

\section{In Vitro-In Vivo Relationship of Meclofenamic Acid and Salts}

Data were treated as described for diclofenac (see above) (Figure 12).

The altered rank order in comparison to diclofenac is evident for both in vivo and in vitro. The in vitro rank order (meclofenamate sodium > meclofenamate DEA > meclofenamic acid) is confirmed by in vivo data.

\section{DISCUSSION AND CONCLUSION}

The IVIVR of both diclofenac and meclofenamic acid demonstrate the possibility of selecting pharmaceutical salts in very early development stages on the basis of in vitro data, which could reduce time and expensive animal studies.

As demonstrated, the cell preparation has an influence on the results. Because of the loose presence of the sample in the large sample cavity, unfavorable standard deviations were obtained (preparation A). The use of a Teflon ring (preparation $\mathrm{C}$ ) ensures that the medium flows evenly through the sample. In preparation B, the medium also flowed around the sample, which decreased the dissolution rate.

For adequate simulation of GIT transit times, the total duration chosen for the combined method was $135 \mathrm{~min}$, subdivided into $45 \mathrm{~min}$ for SGFsp+ and $90 \mathrm{~min}$ for So-SIFsp+. In the literature (22), preprandial time is $1 \mathrm{~h}$ for the stomach and $1-3 \mathrm{~h}$ for the small intestine with the absorption window in the upper part of the small intestine being decisive.
Physiological flow rate is versatile and dependent on many parameters (22); a standard flow rate for dissolution testing is therefore difficult to define. The flow rate is correlated to the end volume because Ph. Eur. 2.9.43. does not prescribe specific volumes. In General Chapters $<711>$ and $<724>$, USP recommends flow rates of 4,8 , and $16 \mathrm{~mL} / \mathrm{min}$ for tablet cells. Because flow rates are correlated to end volumes, this corresponds to 240,480 , and $960 \mathrm{~mL} / \mathrm{h}$ (11). Because of the changed cell volume and geometry, a flow rate of $2 \mathrm{~mL} / \mathrm{min}$ was applied for the implant cell, resulting in a volume of $270 \mathrm{~mL}$ for $135 \mathrm{~min}$. These values correspond to the water intake and drug solubility classification described in the FDA guideline (18) This liquid volume is use for simplification and may not always simulate conditions in vivo. Generally, dissolution is enhanced with increasing flow rate. It is based on the diffusion-layer model, which is based on Fick's law of diffusion. With increasing flow and motion, the diffusion layer thickness is decreased.

In spite of the analogy of diclofenac, meclofenamic acid, and their salts regarding particle size distribution, the in vitro results for these substances exhibit different rank orders. Diclofenac DEA shows a higher dissolution although it has higher particle size values as diclofenac sodium. This may be because of the better solubility properties of diclofenac DEA but is to be investigated. In contrast to these findings, meclofenamic sodium presents the smallest particle size and also the highest dissolution profile as expected from the PSD data. The differences in the in vitro results for all compounds were confirmed by the in vivo data. Based on the IVIVR, the suitability of the developed FTC method was proved.

Regarding the application of poorly soluble compounds, the developed FTC method is suitable for acid as well as basic substances. If bases are used, another time frame for the D.E. determination has to be defined (see above). It must be emphasized that the application of the presented FTC method is only designed for the early development phase to detect first differences of various salts of one API. For refinement of the presented method, further investigations are recommended.

It can be concluded that the FTC represents an easy and economical method for obtaining highly standardized dissolution data for different salts of a new API.The many advantages of the described system may foster the implementation of this dissolution method.

\section{ACKNOWLEDGMENTS}

The authors would like to thank Alfred Fahr, University Jena, Germany; Gert Fricker, University Heidelberg, Germany; and Sven Carsten Poetzsch, Merck KGaA, Germany, for the scientific support.

\section{REFERENCES}

1. Faller, B.; Wohnsland, F. Physicochemical Parameters as Tools in Drug Discovery and Lead Optimization. 
In Pharmacokinetic Optimization in Drug ResearchBiological, Physicochemical, and Computational Strategies; Testa, B., van de Waterbeemd, H., Folkers, G., Guy, R., Eds.;Wiley-VCH:Weinheim, Germany, 2001; pp 257-274.

2. Lipinski, C.A. Drug-like properties and the causes of poor solubility and poor permeability.J. Pharmacol. Tox. Meth. 2000, 44, 235-249.

3. Stegemann, S.; Leveiller, F.; Franchi, D.; de Jong, H.; Lindén, $\mathrm{H}$. When poor solubility becomes an issue: From early stage to proof of concept. Eur. J.Pharm. Sci. 2007, 31, 249-261.

4. Serajuddin, A.T.M. Solid dispersion of poorly watersoluble drugs: Early promises, subsequent problems, and recent breakthroughs. J. Pharm. Sci. 1999, 88, 1058-1066.

5. Rabinow, B. E. Nanosuspensions in Drug Delivery. Nat. Rev. 2004, 3, 785-796.

6. Pinnamaneni, S.; Rao, V. M.; Nerurkar, M.; Rinaldi, F. A.; Raghavan, K. S. Combined Effect of Cyclodextrins and Surfactants on Drug Solubility. Presented at the Annual Meeting of the American Association of Pharmaceutical Scientists, Salt Lake City, Utah, Oct 26-30, 2003.

7. Li, P.; Wagner, R.; Lee, H.; Ghosh, A.; Kabir, M.; Serajuddin, A. Evaluating Self-Microemulsifying Drug Delivery System (SMEDDS) for Poorly Water-Soluble Drugs. Presented at the Annual Meeting of the American Association of Pharmaceutical Scientists, Salt Lake City, Utah, Oct 26-30, 2003.

8. Berge, S. M.; Bighley, L. D.; Monkhouse, D.C. Pharmaceutical Salts. J. Pharm. Sci. 1977, 66, 1-19.

9. Pudipeddi, M.; Serajuddin, A.T.M.; Grant, D. J.W.; Stahl, P.H. Solubility and Dissolution of Weak Acids, Bases, and Salts. In Handbook of Pharmaceutical Salts: Properties, Selection, and Use; Stahl, P. H., Wermuth, C. G., Eds.; Verlag Helvetica Chimica Acta: Zürich, 2002; pp 19-39.

10. Pernarowski, M.;Woo, W.; Searl, R. O. Continuous flow apparatus for the determination of the dissolution characteristics of tablets and capsules. J. Pharm. Sci. 1968, 57 (8), 1419-1421.

11. Langenbucher, F.; Benz, D.; Kürth, W.; Möller, H.; Otz, M. Standardized Flow-cell Method as an Alternative to Existing Pharmacopoeial Dissolution Testing. Pharm. Ind. 1989, 51, 1276-1281.

12. Dokoumetzidis, A.; Macheras, P. A century of dissolution research: From Noyes and Whitney to the Biopharmaceutics Classification System. Int. J. Pharm. 2006, 321, 1-11.

13. Looney, T. J. USP Apparatus 4 (Flow-Through Method) Primer. Dissolution Technol. 1996, 3 (4), 10-12.

14. Krämer, J.; Grady, L. T.; Gajendran, J. Historical Development of Dissolution Testing. In Pharmaceutical Dissolution Testing; Dressman, J. B., Krämer, J., Eds.; Taylor \& Francis Group: Boca Raton, FL, 2005; pp 1-37.
15. Perng, C.-Y.; Kearney, A. S.; Palepu, N. R.; Smith, B. R.; Azzarano, L. M. Assessment of oral bioavailability enhancing approaches for SB-247083 using flowthrough cell dissolution testing as one of the screens. Int. J.Pharm. 2003, 250, 147-156.

16. Shah, V. P.; Konecny, J. J.; Everett, R. L.; McCullough, B.; Noorizadeh, A.C.; Skelly, J. P. In Vitro Dissolution Profile of Water-Insoluble Drug Dosage Forms in the Presence of Surfactants. Pharm. Res. 1989, 6, 612-618.

17. Shah, V. P.; Noory, A.; Noory, C.; McCullough, B.; Clarke, S.; Everett, R.; Naviasky, H.; Srinivasan, B. N.; Fortman, D.; Skelly, J.P. In vitro dissolution of sparingly water-soluble drug dosage forms. Int. J. Pharm. 1995, 125, 99-106.

18. Waiver of In Vivo Bioavailability and Bioequivalence Studies for Immediate-Release Solid Oral Dosage Forms Based on a Biopharmaceutics Classification System; Guidance for Industry; U.S. Department of Health and Human Services, Food and Drug Administration, Center for Drug Evaluation and Research (CDER), U.S. Government Printing Office:Washington, DC, August 2000.

19. Bates, T. R.; Gibaldi, M.; Kanig, J. L. Solubilizing Properties of Bile Salt Solutions I.J. Pharm. Sci. 1966, 55, 191-199.

20. Bates, T. R.; Gibaldi, M.; Kanig, J. L. Solubilizing Properties of Bile Salt Solutions II.J. Pharm. Sci. 1966, 55, 901-906.

21. Vertzoni, M.; Dressman, J.; Butler, J.; Hempenstall, J.; Reppas, C. Simulation of fasting gastric conditions and its importance for the in vivo dissolution of lipophilic compounds. Eur.J.Pharm. Biopharm. 2005, 60, 413-417.

22. Dressman, J. B.; Amidon, G. L.; Reppas, C.; Shah, V.P. Dissolution Testing as a Prognostic Tool for Oral Drug Absorption: Immediate Release Dosage Forms. Pharm. Res. 1998, 15, 11-22.

23. Brown, C. K. Dissolution Method Development: An Industry Perspective. In Pharmaceutical Dissolution Testing; Dressman, J. B., Krämer, J., Eds.; Taylor \& Francis Group: Boca Raton, FL, 2005; pp 351-372.

24. Vertzoni, M.; Fotaki, N.; Kostewicz, E.; Stippler, E.; Leuner, C.; Nicolaides, E.; Dressman, J. B.; Reppas, C. Dissolution media simulating the intralumenal composition of the small intestine: physiological issues and practical aspects. J. Pharm. Pharmacol. 2004, 56 (4), 453-462.

25. Hanson, R.; Gray, V. Handbook of Dissolution Testing, 3rd ed.; Dissolution Technologies, Inc., Hockessin, DE, 2004.

26. Park, S.-H.; Choi, H.-K. The effects of surfactants on the dissolution profiles of poorly water-soluble acidic drugs. Int. J. Pharm. 2006, 321, 35-41.

27. Rohrs, B. R. Dissolution Method Development for Poorly Soluble Compounds. Dissolution Technol. 2001, $8(3), 1-5$.

28. Noory, C.;Tran, N.; Ouderkirk, L.; Shah, V.P. Steps for Development of a Dissolution Test for Sparingly Water-Soluble Drug Products. Dissolution Technol. 2000, 7 (1), 16-19.

29. Handbook of Pharmaceutical Excipients, 2nd ed; Wade, A., Weller, P. J., Eds.; Pharmaceutical Press: Chicago, IL, 1994. 
30. Stippler, E.; Kopp, S.; Dressman, J.B. Comparison of US Pharmacopeia Simulated Intestinal Fluid TS (without pancreatin) and Phosphate Standard Buffer pH 6.8, TS of the International Pharmacopeia with Respect to Their Use in In Vitro Dissolution Testing. Dissolution Technol. 2004, 11 (2), 6-10.

31. Singh, P.; Desai, S. J.; Flanagan, D. R.; Simonelli, A. P.; Higuchi, W. I. Mechanistic study of the influence of micelle solubilization and hydrodynamic factors on the dissolution rate of solid drugs.J.Pharm. Sci. 1968, 57,959-965.

32. Griffith, M. F.; Curley, T.E.; Martin, G.P. Considerations in Choosing a Deaeration Technique for Dissolution Media.Dissolution Technol. 1997, 4 (1), 16-17.

33. Rohrs, B. R.; Stelzer, D. J. Deaeration Techniques for Dissolution Media. Dissolution Technol. 1995, 2 (2), 6-8.

34. Degenhardt, O. S.; Waters, B.; Rebelo-Cameirao, A.; Meyer, A.; Brunner, H.; Toltl, N. P. Comparison of the Effectiveness of Various Deaeration Techniques. Dissolution Technol. 2004, 11 (1), 6-11.

35. Gray, V. A. Compendial Testing Equipment: Calibration, Qualification, and Sources of Error. In Pharmaceutical Dissolution Testing; Krämer, J., Dressman, J. B., Eds.; Taylor \& Francis Group: Boca Raton, FL, 2005; pp 39-68.

36. Wang, Q.; Ma, D.; Higgins, J. P. Analytical Method Selection for Drug Product Dissolution Testing. Dissolution Technol. 2006, 13 (3), 6-13.

37. Zolnik, B. S.; Raton, J.-L.; Burges, D. J. Application of USP Apparatus 4 and In Situ Fiber Optic Analysis to Microsphere Release Testing. Dissolution Technol. 2005, 12 (2), 11-14.

38. Florence, A. J.; Johnston, A. Applications of ATR UV/vis spectroscopy in physical form characterisation of pharmaceuticals. Spectrosc. Eur. 2004, 16, 24-27.

39. Brown, C. K.; Chokshi, H. P.; Nickerson, B.; Reed, R. A.; Rohrs, B. R.; Shah, P. A. Acceptable Analytical Practices for Dissolution Testing of Poorly Soluble Compounds. Pharm. Technol. 2004, 28 (12), 56-65.

40. Nicklasson, M. A collaborative study of the in vitro dissolution of phencetin crystals comparing the flow-through method with the USP Paddle method. Int. J. Pharm. 1991, 69, 255-264.

41. Derendorf, H.; Drehsen, G.; Rohdewald, P. In vivo-in vitro correlations of salicylate saliva levels and continuous flow cell dissolution rates. Int. J. Pharm. 1983, 15, 167-175.

42. Phillips, J. G.; Chen, Y.; Wakeling, I. N. A flow-through dissolution approach to in vivo/in vitro correlation of adinazolam release from sustained release formulations. Drug Dev. Ind. Pharm. 1989, 15, 2177-2195.

43. Qureshi, S. A.; Caillé, C.; Brien, R.; Piccirilli, G.;Yu, V.; McGilveray, I. J. Application of Flow-Through Dissolution Method for the Evaluation of Oral Formulations of Nifedipine. Drug Dev. Ind. Pharm. 1994, 20, 1869-1882.

44. Sunesen, V.H.; Pedersen, B. L.; Kristensen, H. G.; Müllertz, A. In vivo in vitro correlations for a poorly soluble drug, danazol, using the flow-through dissolution method with biorelevant dissolution media. Eur. J. Pharm. Sci. 2005, 24, 305-313.

45. Potthast, H.; Mircioiu, I.; Bastian, B.; Möller, H. Biopharmazeutische Charakterisierung von Diclofenac-Präparaten. Pharm.Ztg. 2001,45, 1-10.

46. Chiou, W. I.; Barve, A. Linear Correlation of the Fraction of Oral Dose Absorbed of 64 Drugs between Humans and Rats. Pharm. Res. 1998, 15, 1792-1795.

47. Clarke's Analysis of Drugs and Poisons, 3rd ed.; Moffat, A. C., Osselton, M. D., Widdop, B., Galichet, L. Y., Eds.; Pharmaceutical Press: Chicago, IL, 2004.

48. Zhao, Y.H.; Abraham, M.H.; Le, J.; Hersey, A.; Luscombe, C. N.; Beck, G.; Sherborne, G.; Cooper, I. Evaluation of rat intestinal absorption data and correlation with human intestinal absorption. Eur.J.Med. Chem. 2003, 38, 233-243.

49. International Organization for Standardization. ISO 13320-1. Particle size analysis-Laser diffraction methods; Geneva, 1999.

50. Khan, K. A. The concept of dissolution efficiency. J. Pharm. Pharmacol. 1975, 27, 28-49.

51. Siewert, M. FIP Guidelines for Dissolution Testing of Solid Oral Products. Pharm. Ind. 1997, 59, 760-766.

52. Emami, J. In vitro-in vivo Correlation: From Theory to Applications. J.Pharm. Pharm. Sci. 2006, 9, 31-51.

53. Zhao, F.; Malayev, V.; Rao, V.; Hussain, M. Effect of Sodium Lauryl Sulfate in Dissolution Media on Dissolution of Hard Gelatin Capsule Shells. Pharm. Res. 2004, 21, 144-148.

54. Gander, B.; Ventouras, K.; Gurny, R.; Doelker, E. In vitro dissolution medium with supramicellar surfactant concentration and its relevance for in vivo absorption. Int. J. Pharm. 1985, 27, 117-124.

55. Finholt, P.; Solvang, S. Dissolution kinetics of drugs in human gastric juice: The role of surface tension. J. Pharm. Sci. 1968, 57, 1322-1326.

56. Fell, J.T.; Mohammad, H. A. H. The wetting of powders by bile salt solutions and gastric juice. Int. J. Pharm. 1995, 125, 327-330. 